\title{
Effect of Galvannealed Coating Evolution during Press Hardening on RSW Weldability
}

\author{
This research revealed increasing heat-treatment time shifted \\ the process window toward lower current
}

\author{
BY X. HAN, M. H. RAZMPOOSH, A. MACWAN, E. BIRO, AND Y. ZHOU
}

\begin{abstract}
Press-hardening steels (PHSs) are used in modern passenger vehicles to increase part strength while reducing vehicle weight to meet both environmental and safety regulations. To prevent oxidization and decarburization during heat treatment, some PHSs are coated with Zn (galvanized or galvannealed). Heating during the press-hardening process drives interdiffusion of $\mathrm{Zn}$ from the coating and the Fe from the steel substrate, forming a diffusion layer composed of $\alpha$-Fe phase (a Zn-Fe solid solution). The electrical resistance of the diffusion layer is a function of its thickness and Zn-Fe composition. Both the diffusion layer thickness and the Zn-Fe composition are dependent on the initial coating thickness and heat-treatment time/temperature conditions. Changes to the heat-treatment process shift the resistance spot welding process window by altering the resistance behavior of the material. If the shift in the process window is not accounted for during assembly welding, the welds produced may either be too small or exhibit expulsion, both of which will reduce the strength of the weld. This study showed increasing heattreatment time shifted the process window toward lower current. A final combined processing window of $1.5 \mathrm{kA}$, which is suitable for industrial application, was obtained when taking into account the variation in heat-treatment time. The tensile shear performance was not affected by the heat treatment, as increased softening in the heat-affected zone at longer heat-treatment time canceled the strength gain from increasing nugget size.
\end{abstract}

\section{KEYWORDS}

- Resistance Spot Welding • Press-Hardening Steel

- Zn Coating • Tensile Strength • Microstructure

\section{Introduction}

Lightweighting has been regarded as a key strategy in the automotive industries to meet increasingly strict emission standards while achieving higher safety performance (Ref. 1). Lightweighting is mainly achieved by reducing the thickness of the sheet steels used to produce automotive parts for the body-in-white (BIW). By using higher strength steels, part strength may be retained while material thickness is reduced. Press-hardening steel (PHS) has emerged as a suitable candidate for lightweighting applications, where its fully martensitic structure provides extremely high strength and a similar level of passenger protection, allowing thinner steel gauges to be used (Refs. 2, 3).

A PHS undergoes a press-hardening process, where it is formed at a high temperature to achieve the final martensitic structure. During press hardening, a PHS sheet is first heated above the austenitization temperature and held for a set time to ensure full austenitization. While hot, the PHS is transferred into a water-cooled forming die for the in-die quenching process. In-die quenching forms and cools the PHS sheet, allowing high formability during this process and a high cooling rate to transform austenite into the desired martensitic microstructure (Refs. 2, 3). During press hardening, surface coatings are necessary to protect the steel from severe oxidation and decarburization. Zinc-based coatings provide effective protection during press hardening as well as further in-service corrosion protection (Refs. 4-6). During heat treatment, long holding time at the austenitization temperature results in $\mathrm{Zn}$-Fe interdiffusion between the coating and steel substrate, and oxides formation from interaction with the ambient atmosphere of the furnace. The interdiffusion and the oxidation depend both on the temperature and time of the heat-treatment stage of press hardening (Ref. 7). Considering that, heat-treatment time and temperature are varied due to sheet thickness and manufacturing requirements to ensure a full austenitization of the materials, the final thickness, and Fe-Zn composition of the diffusion layer may vary depending on the specific heattreatment conditions used (Refs. 8, 9).

Variation in the diffusion layer affects the resistivity of the material and consequently changes its resistance spot welding (RSW) behavior. This poses concerns with respect to the robustness of the RSW process when joining GAcoated PHS. Therefore, it is important to understand the Zn diffusion layer effects on RSW to ensure process robustness. The current study investigated the relationship of heat-treatment conditions to the diffusion layer growth, 


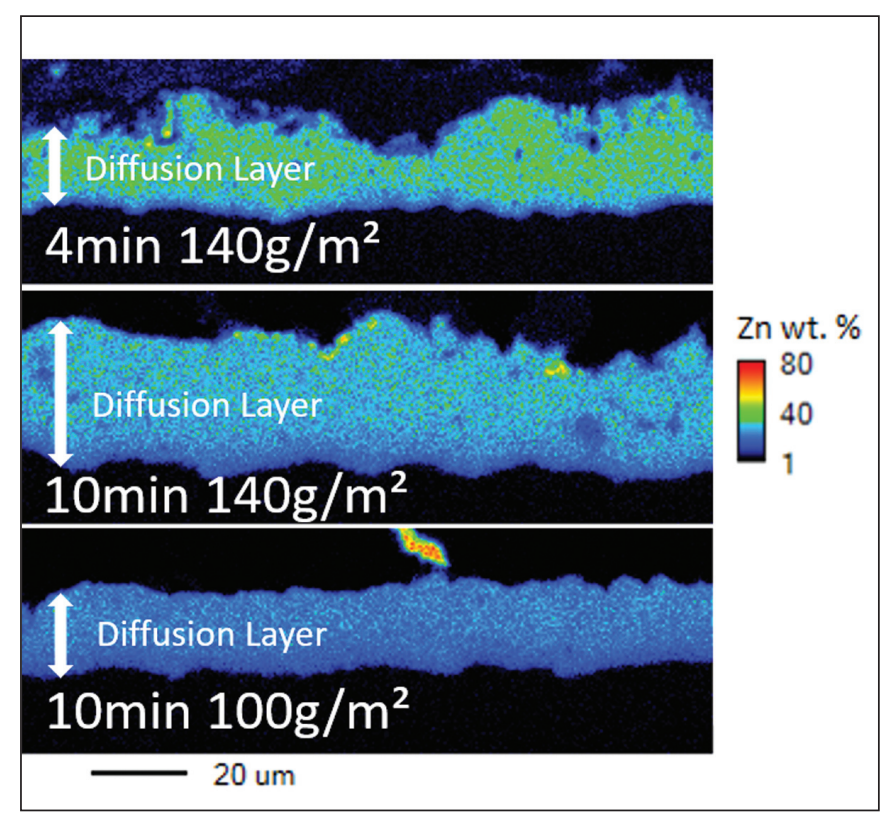

Fig. 1-EPMA scan in the surface layer of a treated and sandblasted cross section showing distributions of $\mathrm{Zn}$ content.

and their effect on the RSW process window of Zn-coated PHS and its subsequent effect on mechanical properties.

\section{Material and Experimental Procedure}

\section{Material Preparation}

In this study, 2-mm-thick GA-coated 22MnB5 steel sheets (Table 1) with two different total coating weights of 100 and $120 \mathrm{~g} / \mathrm{m}^{2}$ were used. The as-received sheets were heat treated in an open-air environment at $860^{\circ} \mathrm{C}$ for 4,7 , and $10 \mathrm{~min}$. After the heating stage, the sheets were rapidly transferred $(<5$ s) into a water-chilled quenching die set with a surface temperature less than $50^{\circ} \mathrm{C}$ to achieve high cooling rate and final martensitic microstructure. The processed sheets were laser cut into $25 \times 25 \mathrm{~mm}(1 \times 1 \mathrm{in}$.) coupons for welds that were to be analyzed metallographically, and $25 \times 100 \mathrm{~mm}(1 \times 4 \mathrm{in}$.) strips for welds to be mechanically tested in tensile shear. Before welding, all coupons were sandblasted to remove the top oxide layer created during press hardening. The metallographic examination confirmed sandblasting did not disrupt the integrity of the diffusion layer (Ref. 10).

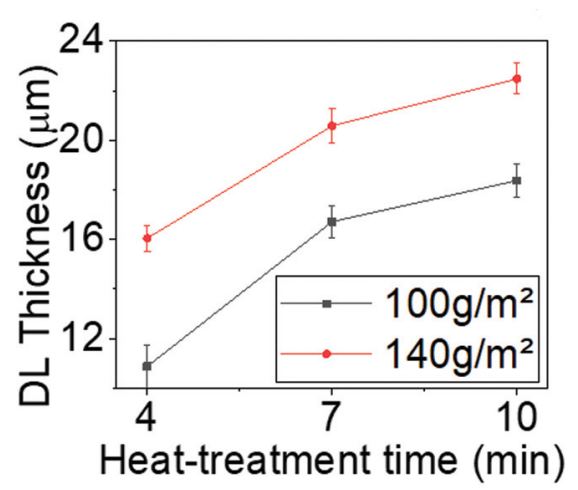

A

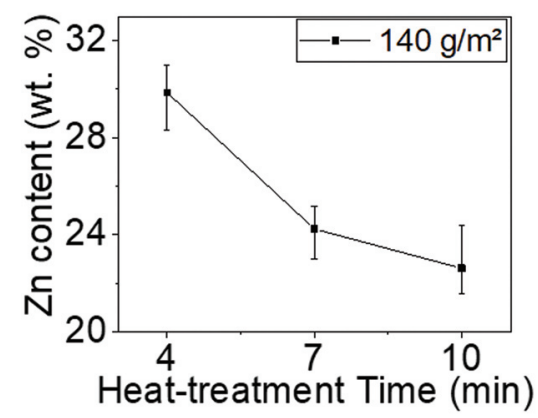

B

Fig. 2 - A - The diffusion layer thickness; B - EPMA Zn content at different heat-treatment conditions.

\section{Resistance Spot Welding (RSW)}

Resistance spot welding was performed using mediumfrequency direct current welding equipment with a Rexroth weld controller operating under the constant current mode. Welding parameters were chosen based on the AWS D8.9 Standard (Ref. 11) (Table 2). While the AWS D8.9 Standard is based on alternating current power supply, its specified parameter can also be applicable in the case of direct current welding machines. Due to machine set-up limitations, an electrode face diameter of $6 \mathrm{~mm}(1 / 4 \mathrm{in}$.) and electrode force of $5.4 \mathrm{kN}$ (1200 lbf) was used instead of the $8 \mathrm{~mm}$ ( $5 / 16 \mathrm{in}$.) diameter and $7.2 \mathrm{kN}$ (1600 lbf) force required by the AWS D8.9 Standard (Ref. 11). Welding time was converted and rounded from the $60-\mathrm{Hz}$ cycles to milliseconds (ms) used by the weld controller. The weld schedule consists of three welding pulses of $167 \mathrm{~ms}$ separated by two cooling pulses of $33 \mathrm{~ms}$ (Table 2).

Table 1-Chemical Composition (wt-\%) of the Experimental 22MNB5 Press-Hardening Steel

\begin{tabular}{ccccccccccc} 
C & Mn & Si & P & S & Al & Cr & Ti & B & Fe \\
\hline 0.23 & 1.19 & 0.25 & 0.016 & 0.002 & 0.05 & 0.20 & 0.03 & 0.003 & Bal.
\end{tabular}

Table 2 - Modified Welding Schedule Adapted from AWS Standard D8.9 (Ref. 11)

\begin{tabular}{cccccc} 
Sheet Thickness & Electrode Diameter & Force & Cooling & Weld Sequence (ms) & Hold Time (ms) \\
\hline $2 \mathrm{~mm}(1 / 16 \mathrm{in})$. & $6 \mathrm{~mm}(1 / 4 \mathrm{in})$. & $5.4 \mathrm{kN}(1200 \mathrm{lbf})$ & $\begin{array}{c}6 \mathrm{~L} / \mathrm{min} \\
(1.6 \mathrm{gal} / \mathrm{min})\end{array}$ & $167-33-167-33-167$ & 167 \\
\end{tabular}



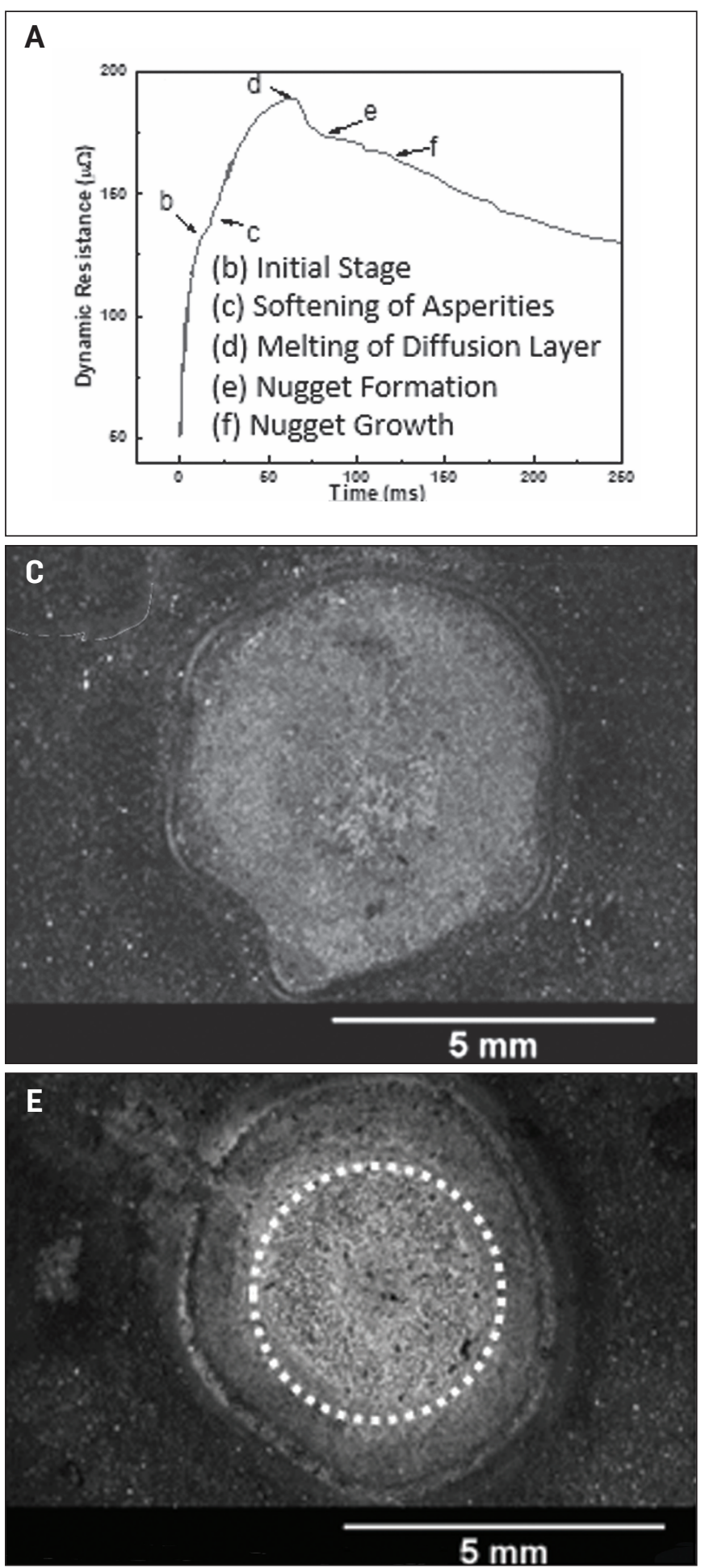
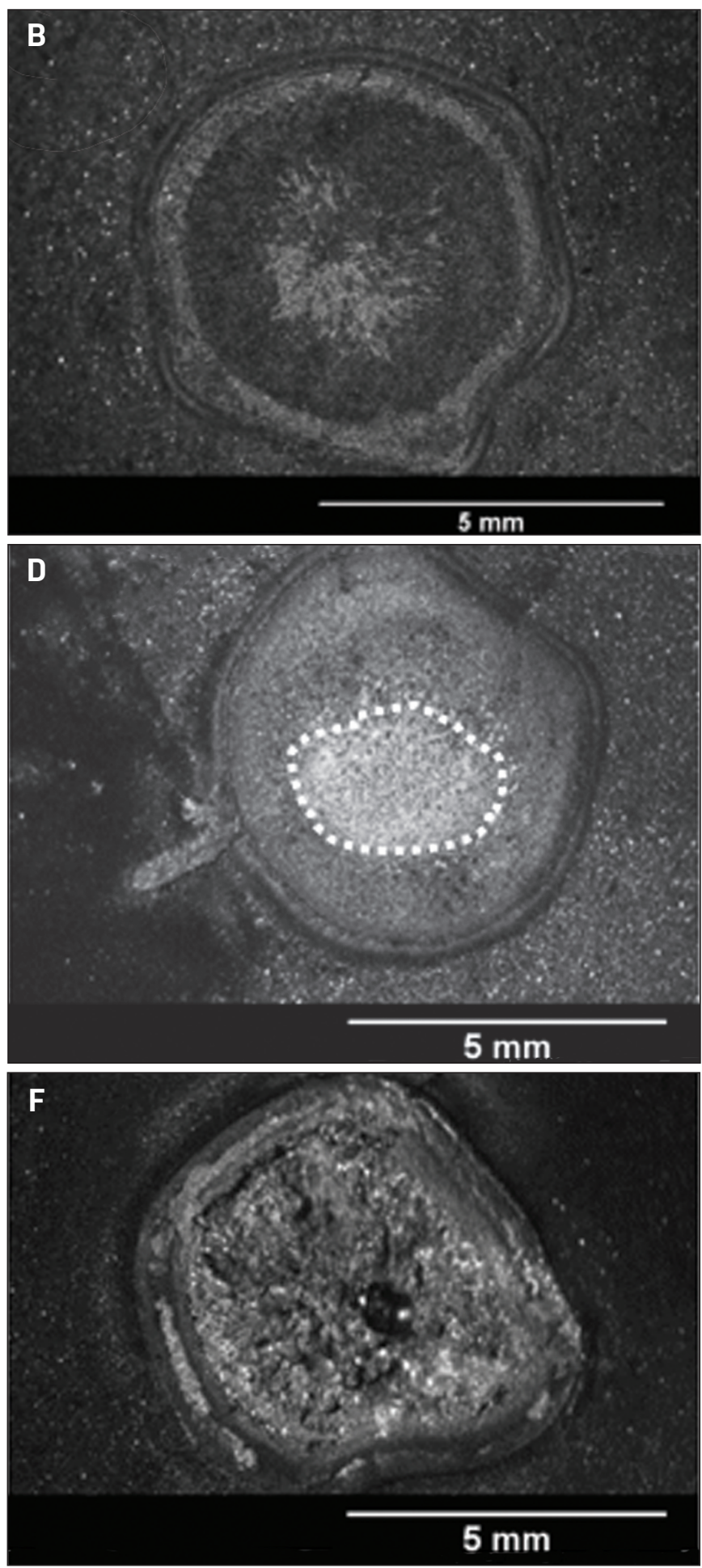

Fig. $3-A-$ Interrupted tests correspond to the dynamic resistance curve; $B-F-i$ its interfacial condition.

The dynamic resistance measurements were calculated using real-time voltage and current value acquired using the weld control timer. Interrupted tests were performed by reducing welding time to study the evolution of the contact surface and the effects of the diffusion layer on welding behavior. Weld size was measured by peel test and cross-sectional metallographic examination to measure the nugget size.

\section{Microstructure Characterization and Mechanical Testing}

To evaluate the microstructure and nugget size, welds were cross sectioned, mounted, polished, and etched using 5\% nital. The microstructure was investigated using an Olympus optical microscope and Zeiss Leo 1530 field emission scanning elec- 

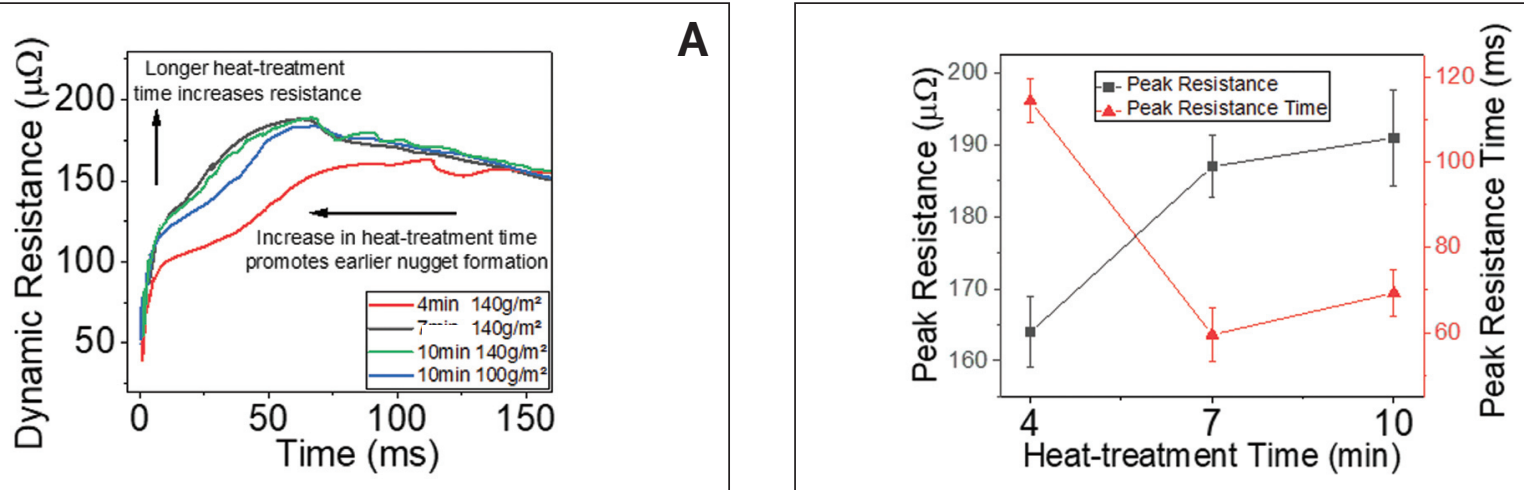

Fig. 4-A - Dynamic resistance measurement for different heat-treatment conditions; $B$ - the peak resistance (black) and the time when the peak resistance was reached (red) for different heat-treatment times.

tron microscopy (FE-SEM). To characterize the coating evolution after the heat-treatment process, electron probe microanalyzer (EPMA) characterization was performed on the diffusion layer to identify element mapping. Hardness testing was performed using a Clemex-JS2000 Vickers indenter with digital stage control. Indentations were made using a load of $300 \mathrm{~g}$ (0.67 lbf) and a dwell time of $15 \mathrm{~s}$. Shear tension testing was performed using an Instron tensile frame with a cross-head speed of $5 \mathrm{~mm} / \mathrm{min}$.

\section{Results and Discussion}

\section{Fe-Zn Diffusion Layer Evolution}

After heat treatment, the $\delta$ and $\Gamma-\Gamma 1$ phases of the asreceived GA coating (Ref. 12) evolved into a Fe-Zn diffusion layer (uniform solid solution of $\mathrm{Zn}$ in alpha-Fe), as shown in Fig. 1.

The diffusion layer thickness increased with increasing heat-treatment time and GA-coating weight (see Fig. 2). As heat-treatment time increased, the $\mathrm{Zn}$ had more time to diffuse deeper into the steel matrix, forming a thicker diffusion layer. However, it should be noted the thickness increase was not linear with respect to heat-treatment time. Larger growth of the diffusion layer was observed between samples treated for 4 and 7 min compared to the growth between samples heat treated for 7 and $10 \mathrm{~min}$. The observed progression of the diffusion layer with respect to time confirms this was a diffusion driven process, as diffusion distance increased as a function of the square root of time (Ref. 7). In addition to the diffusion kinetics, the effective time over which the diffusion occurred was not the whole heat-treatment time. After entering the furnace, the sample needed time to heat to a temperature where significant diffusion began, further showing why a larger difference was observed at a shorter heat-treatment time. Similarly, additional $\mathrm{Zn}$ was available for diffusion when increasing the coating weight, resulting in a thicker diffusion layer.

It was also observed, as shown in Fig. 2B, that the concentration of $\mathrm{Zn}$ in the diffusion layer decreased with increasing heat-treatment time. With the increase in diffusion depth at longer heat-treatment time, $\mathrm{Zn}$ was naturally dispersed in the diffusion layer, causing a decrease in $\mathrm{Zn}$ concentration. Furthermore, the total $\mathrm{Zn}$ content of the layer decreased as a result of the growth of a $\mathrm{ZnO}$ layer that formed during heat

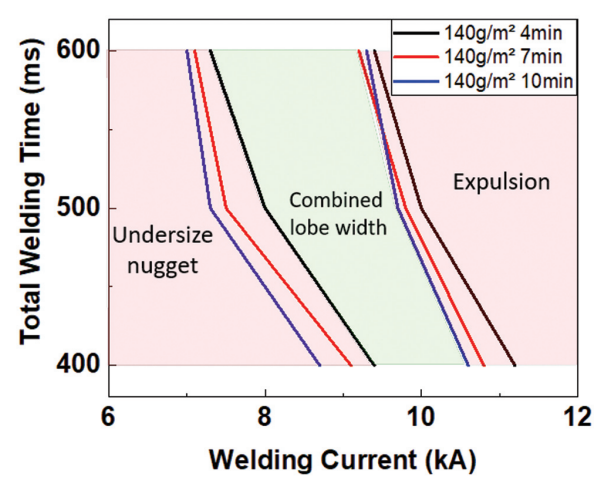

Fig. $5-$ Resistance spot weld lobe indicating the range of acceptable welding current and total time of the three welding pulses (in green) and expulsion/undersize nugget region (in red) for different heat-treatment conditions.

treating. The formations of the $\mathrm{ZnO}$ layer reduced the availability of $\mathrm{Zn}$ in the diffusion layer, further reducing the concentration of $\mathrm{Zn}$ in prolonged heat-treated samples. It should be noted that the $\mathrm{ZnO}$ layer will not contribute to the welding behavior, as the oxide layer was removed by sandblasting prior to welding in the present study.

\section{Dynamic and Resistive Measurement, Correlation}

There are two components that make up dynamic resistance during spot welding: contact resistance at the faying surface and bulk resistance through the material (Ref. 13). Contact resistance is mainly governed by contact surface conditions, while bulk resistance is governed by the material properties and temperature (Ref. 13). Using the interrupted test, different stages of the RSW process can be linked to features in the dynamic resistance curve, which are labeled with time stamps from $b$ to $f-$ Fig. 3 .

Since the instantaneous resistance measurement was based on electric current and voltage measurement, resistance readings sampled before time stamp $\mathrm{b}$ were affected by the current change and were not representative of the actual sample condition. At point $b$ in the cycle, asperity softening began as temperature at the interface started to increase - 

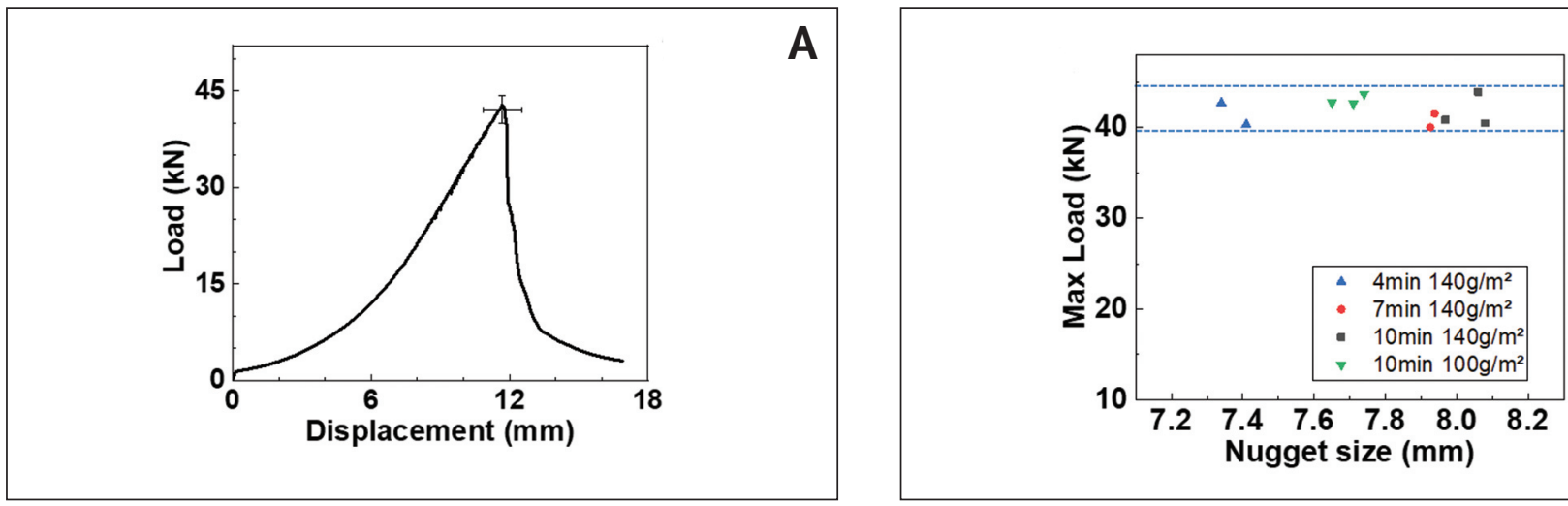

Fig. 6-A - A representative load-displacement curve; B - comparison of the maximum load based on the nugget size obtained under the same welding parameters.
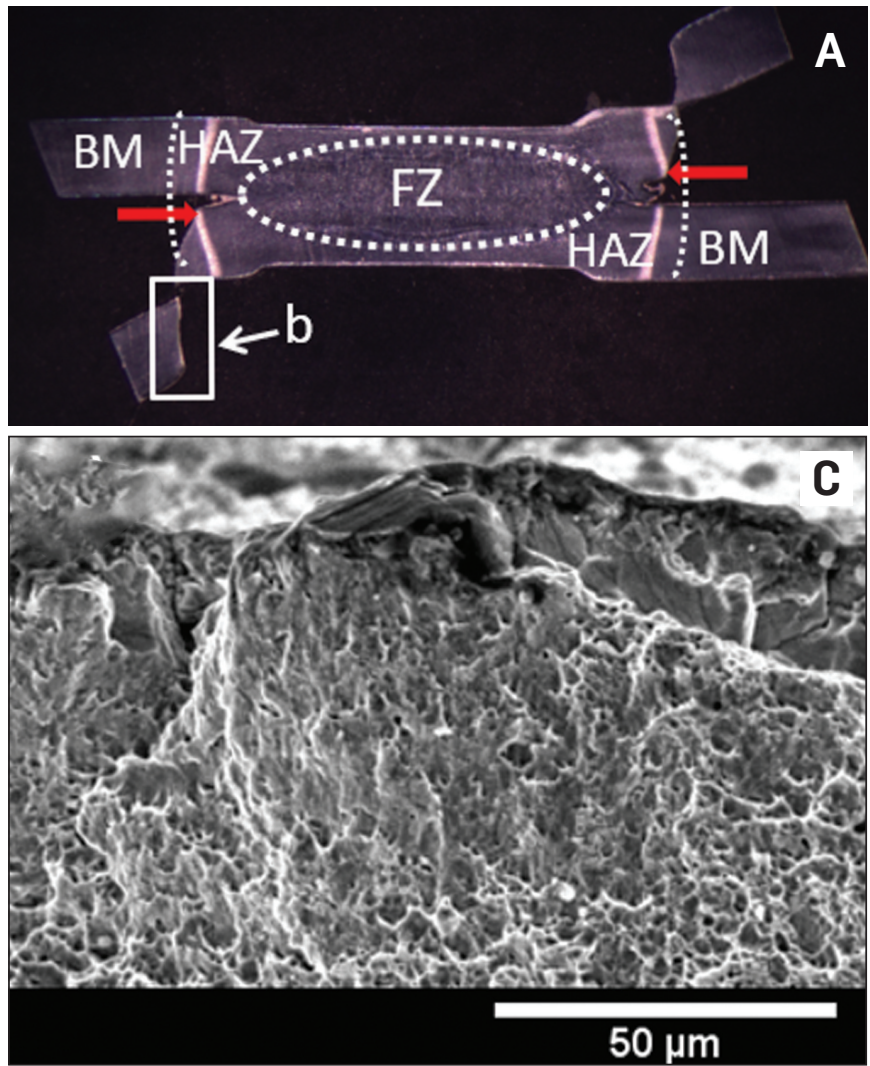
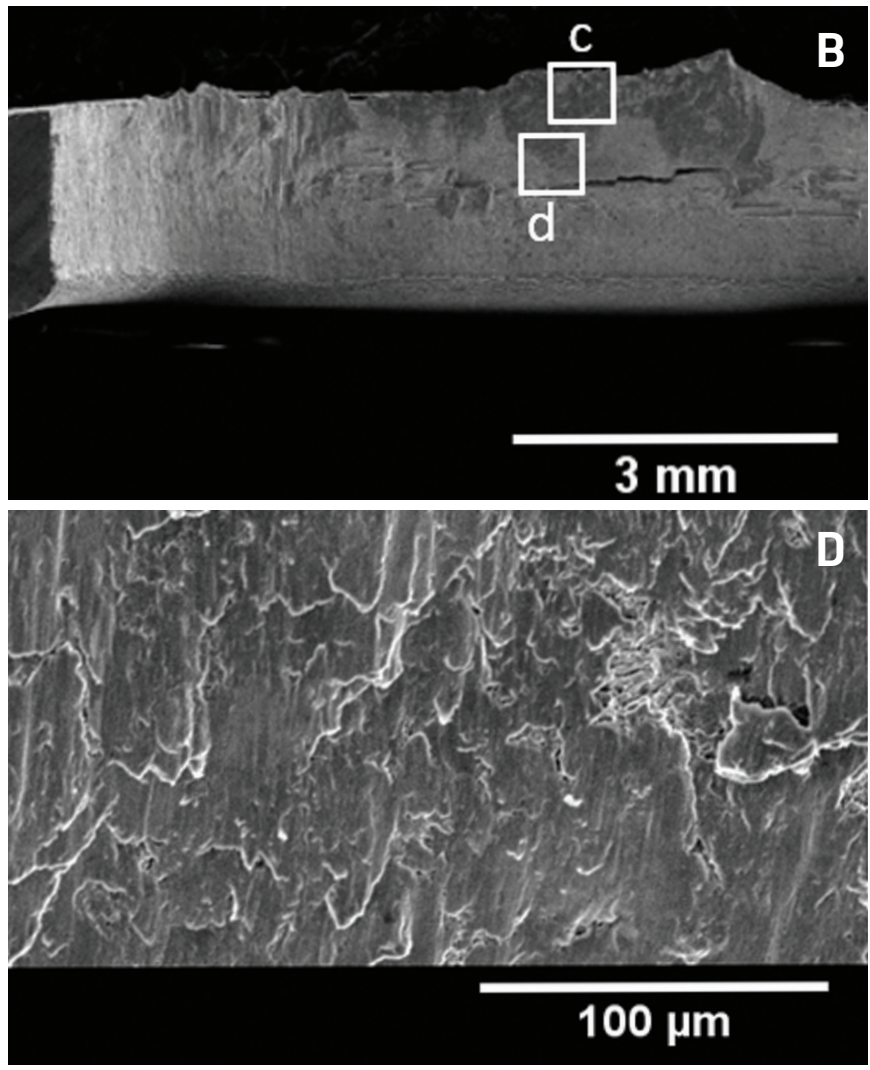

Fig. 7-A - Macroscopic cross-sectional view of the button pull-out failure with the red arrows indicating the failure initiation points; $B$ - fracture surface under SEM; C - ductile failure at the crack initiation; $D$ - failure transition into the brittle mode as it propagates.

Fig. 3B. The change in dynamic resistance was primarily due to the reduction in contacting surface asperities and heating of the bulk material. When heated, asperities on the contact surface soften, flattened by the electrode and contributing to a decrease in dynamic resistance (Ref. 13). However, increasing temperature increased the bulk resistance, resulting in a continued overall increase in dynamic resistance. At point c, asperity softening was completed (Fig. 3C), which resulted in a change of slope as shown in Fig. 3A. Immediately before reaching point $d$, the faying surface started to melt - Fig. 3D. Due to the presence of $\mathrm{Zn}$, the diffusion layer had a lower melting temperature compared to the steel substrate (Ref. 14), which resulted in the earlier melting.
Presence of liquid phase reduced dynamic resistance at time $\mathrm{d}$, resulting in the resistance peak. In addition to the melting, the electrode force further spread the liquid across the faying surface, effectively increasing the contact surface Fig. 3D. Time point $d$ was also referred to as the peak resistance time, as it was the time required for the weld to reach its resistance peak. After the diffusion layer starts to melt at point $d$, steel substrate melting occurs at the interface, forming the molten nugget. As the area of molten surface increased, dynamic resistance further decreased - Fig. 3E. Beyond time point $\mathrm{f}$, dynamic resistance reduced as the nugget grew (Fig. 3F), until either the welding cycle was completed or expulsion occurred. The occurrence of expul- 

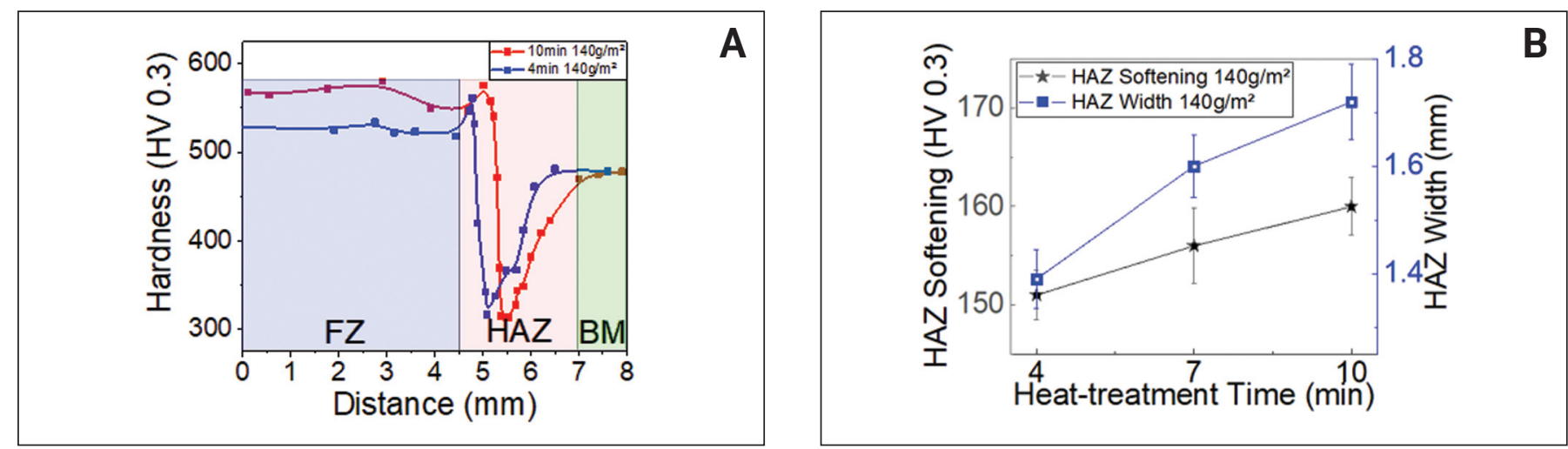

Fig. 8 - A - Hardness profile showing the fusion zone, HAZ, and the base material; B - hardness drop in the HAZ region compared to the base material strength and the HAZ width in different heat-treatment conditions.

sion was due to excessive amounts of heat introduced into the system. When the weld nugget grew beyond the electrode's capability to retain it, liquid metal was ejected from the nugget pool. Ejected metal forms a shunting pass around the nugget area, preventing further growth of the nugget. Since nugget growth was stopped, minimal changes to the dynamic curve were observed post expulsion.

With an understanding of the correlation between dynamic resistance and surface condition, the dynamic resistance curve can be used to compare the difference between welding behavior in the different heat-treatment conditions, as shown in Fig. 4. Higher initial and peak resistances were observed in samples with a longer heat-treatment time - Fig. 4. Higher resistance indicates there will be more heat-generation due to Joule heating, which accelerates melting at the contact surface. As shown in Fig. 3, nugget formation starts right after the peak resistance was reached. Therefore, the earlier peak resistance observed with longer heat treatment time indicated an earlier nugget formation. It is worth noting a similar peak resistance was measured for the heat-treatment time of 7 and $10 \mathrm{~min}-$ Fig. 4B. This similarity came from the minimal difference in the diffusion layer thickness and $\mathrm{Zn}$-Fe composition between the two heat-treatment times - Fig. 2. Once the nugget growth started, the dynamic resistance between different diffusion layer conditions became similar because the diffusion layer was consumed by the nugget and could no longer contribute to the resistivity increase.

\section{Change in Weld Size and Weld Lobe}

The processing window in RSW can be described using the weld lobe. The minimum nugget curves (Fig. 5) indicated the required parameters to achieve the minimum nugget diameter $d=t^{*} \sqrt{ }(t)$, where $c$ is a constant and $t$ is the sheet thickness. While AWS D8.9 (Ref. 11) requires the c value of 4.0, other studies have suggested 4.0 is not enough for higher strength materials such as PHS (Ref. 15). Hence, the c value of 4.5 was used in this study due to the high strength of PHS. The expulsion curve indicates the parameters where three consecutive expulsions were observed, which is considered the maximum current - Fig. 5.

Weld lobe curve width and locations were both affected by different heat treatment, as shown in Fig. 5. It was observed that material heat treated for longer times had weld lobes that were shifted to the left of materials heat treated for shorter times. When the weld lobe was farther left, it indicated less current was required to achieve the minimum nugget size. Similarly, this increase in resistance lowered the expulsion current limit. This observation agreed with the dynamic resistance results, showing longer heat-treated samples had higher resistance and reached their peak resistance earlier in the weld cycle - Fig. 4B. The lobe shifting is less severe at a longer welding time. As heat generation from contact resistance was greatly reduced after the nugget growth started, longer welding time reduced the impact of surface conditions as a proportion of heat generated from bulk heating increased. The width of the weld lobe also increased by $0.5 \mathrm{kA}$ when heat treatment was increased from 4 to $10 \mathrm{~min}$; however, it should be noted all the conditions had a lobe width above $2 \mathrm{kA}$ at the suggested total welding time of $500 \mathrm{~ms}$ - Fig. 5. To take into consideration the change in diffusion layer because of varied heat-treatment condition, a combined lobe with the extreme conditions (highest minimum nugget and lowest expulsion limits) was constructed. From the combined lobe, an effective operating window above $1.5 \mathrm{kA}$ was observed at a 500 -ms welding time when heat treating time was not controlled. This lobe width was commonly reported for a robust RSW process in a manufacturing environment (Refs. 16, 17).

\section{Difference in Mechanical Performance and Hardness Measurement}

Under tensile shear loading, all loads exceeded $40 \mathrm{kN}$. A representative load-displacement curve is shown in Fig. 6A and all samples failed in button pull-out mode - Fig. 7A. When welded using the same welding parameters, no difference in the maximum load was observed, despite the difference in nugget size due to the different heat-treating schedule and zinc thickness - Fig. 6B. To investigate this, a detailed analysis of the fracture surface after tensile testing was performed. It was found fracture initiated in the heat-affected zone (HAZ) and outside of the nugget area - Fig. 7A. The fracture surface was further characterized using SEM - Fig. 7B. A closer inspection of the crack initiation area (Fig. 7C) revealed fracture occurred in a ductile fashion. As the crack propagated during loading, the failure mode became increasingly brittle with signs of cleavage cracking as the load direction is constantly changing - Fig. 7D. This initial ductile fracture in- 
dicates microstructural changes in the $\mathrm{HAZ}$ are indeed the fracture initiation point. Further analysis of the HAZ can help understanding why increasing nugget size did not increase the joint strength.

The hardness profiles across the welds were measured to understand how heat-treatment conditions affect the HAZ when welded with consistent parameters - Fig. 8A. The fusion zone and base metal both had a high hardness due to their martensitic structure. However, significant softening was observed over the HAZ, which is associated with tempering of martensite that consequently affects the strength of the joint (Refs. 18, 19). Figure 8B shows that with increasing heat-treatment time, both the width of HAZ and degree of softening increased, resulting in a higher loss in strength at a longer heattreatment time. Therefore, higher heat introduced to the weld should have reduced the mechanical strength of the joints. However, with higher resistance at the higher heat-treatment time, increased heat input also created a larger nugget, which increased the joint strength. The effect of increasing nugget size was compensated by the decrease in HAZ strength, explaining the similar tensile shear strength obtained from the different heat-treatment conditions - Fig. 6B.

\section{Conclusions}

Changing the heat-treatment condition of press-hardening varied both the thickness and chemical composition of the $\mathrm{Zn}$ Fe diffusion layer at the sample surface. The processing window for these different conditions had been measured and their mechanical performance compared using a conventional welding schedule with the following conclusions:

1) Prolonged heat-treating time and higher initial coating weight both increased the thickness of the diffusion layer. The Zn content increased with higher initial coating weight and reduced with prolonged heat-treatment. Longer heat-treatment time shifted the weld lobe curve toward lower welding current.

2) Weld lobe shift resulted from the change in resistance profile. Under the constant current mode, higher dynamic resistance measured in prolonged heat-treatment conditions led to higher heat-generation during welding and larger final nugget diameters.

3) An individual weld lobe of at least $2 \mathrm{kA}$ was observed for resistance spot welding of press-hardened steel heat-treated between 4 and $10 \mathrm{~min}$ at $860^{\circ} \mathrm{C}$. With increasing heat-treatment time, the lobe curve shifts toward the left. A combined overall weld lobe width of $1.5 \mathrm{kA}$ was observed at 500-ms weld time.

4) Button pull-out failure was obtained when welding in the acceptable range of the processing window where softened HAZ being the failure initiation point. Consistent tensile shear strength was observed in different conditions.

\section{References}

1. Kim, H. C., and Wallington, T. J. 2013. Life-cycle energy and greenhouse gas emission benefits of lightweighting in automobiles: Review and harmonization. Environmental Science \& Technology 47: 6089-6097.

2. Turetta, A., Bruschi, S., and Ghiotti, A. 2006. Investigation of $22 \mathrm{MnB} 5$ formability in hot stamping operations. Journal of Materi- als Processing Technology 177(1-3): 396-400.

3. Fan, D. W., Kim, H. S., and De Cooman, B. C. 2009. A review of the physical metallurgy related to the hot press forming of advanced high strength steel. Steel Research International 80(3): 241-248.

4. Asgari, H., Toroghinejad, M. R., and Golozar, M. A. 2007. On texture, corrosion resistance and morphology of hot-dip galvanized zinc coatings. Applied Surface Science 253(16): 6769-6777.

5. Pistofidis, N., Vourlias, G., Konidaris, S., Pavlidou, E., Stergiou, A., and Stergioudis, G. 2006. Microstructure of zinc hot-dip galvanized coatings used for corrosion protection. Materials Letters 60(6): 786-789.

6. Razmpoosh, M. H., Macwan, A., Biro, E., Chen, D. L., Peng, Y., Goodwin, F., and Zhou, Y. 2018. Liquid metal embrittlement in laser beam welding of Zn-coated 22MnB5 steel. Materials \& Design 155: 375-383.

7. Shewmon, P. 2016. Diffusion in Solids. Springer.

8. Ighodaro, O. L., Biro, E., and Zhou, N. Y. 2017. Study and applications of dynamic resistance profiles during resistance spot welding of coated hot-stamping steels. Metallurgical and Materials Transactions A 48(2): 745-758.

9. Ighodaro, O. L., Biro, E., and Zhou, N. Y. 2016. Comparative effects of $\mathrm{Al}-\mathrm{Si}$ and galvannealed coatings on the properties of resistance spot welded hot stamping steel joints. Journal of Materials Processing Technology 236: 64-72.

10. Windmann, M., Röttger, A., Kügler, H., and Theisen, W. 2016. Removal of oxides and brittle coating constituents at the surface of coated hot-forming $22 \mathrm{MnB} 5$ steel for a laser welding process with aluminum alloys. Surface and Coatings Technology 285: 153-160.

11. American Welding Society. 2012. D8.9M:2012, Test Methods for Evaluating the Resistance Spot Welding Behavior of Automotive Sheet Steel Materials.

12. Razmpoosh, M. H., Macwan, A., Biro, E., and Zhou, Y. 2018. Effect of coating weight on fiber laser welding of galvanneal-coated 22MnB5 press hardening steel. Surface and Coatings Technology 337: 536-543.

13. Williams, N. T., and Parker, J. D. 2004. Review of resistance spot welding of steel sheets Part 1 Modelling and control of weld nugget formation. International Materials Reviews 49: 45-75.

14. Han, K., Ohnuma, I., Okuda, K., and Kainuma, R. 2018. Experimental determination of phase diagram in the $\mathrm{Zn}-\mathrm{Fe}$ binary system. Journal of Alloys and Compounds 737: 490-504.

15. Sun, X., Stephens, E. V., and Khaleel, M. A. 2008. Effects of fusion zone size and failure mode on peak load and energy absorption of advanced high strength steel spot welds under lap shear loading conditions. Engineering Failure Analysis 15(4): 356-367.

16. Ming, L., and Hua, P. 2012. Comparative study of resistance spot welding performance between cold-rolled DP980 and Q\&P980 steels. Baosteel Technical Research 6(1): 37.

17. Hwang, I. S., Kang, M. J., and Kim, D. C. 2011. Expulsion reduction in resistance spot welding by controlling of welding current waveform. Procedia Engineering 10: 2775-2781.

18. Biro, E., McDermid, J. R., Embury, J. D., and Zhou, N. Y. 2010. Softening kinetics in the subcritical heat-affected zone of dual-phase steel welds. Metallurgical and Materials Transactions A 41(9): 2348-2356.

19. Xia, M., Sreenivasan, N., Lawson, S., Zhou, N. Y., and Tian, Z. 2007. A comparative study of formability of diode laser welds in DP980 and HSLA steels. Journal of Engineering Materials and Technology 129(3): 446-452.

X. HAN (xu.han.1@uwaterloo.ca), M. H. RAZMPOOSH, E. BIRO, and $Y$. ZHOU are with the Centre for Advanced Materials Joining, Department of Mechanical \& Mechatronics Engineering, University of Waterloo, Waterloo, Ontario, Canada. A. MACWAN is with ArcelorMittal Global Research, Hamilton, Canada. 